\title{
Genomic evaluation, breed identification, and population structure of Guernsey cattle in North America, Great Britain, and the Isle of Guernsey
}

\author{
T. A. Cooper, ${ }^{*}$ S. A. E. Eaglen,† G. R. Wiggans, ${ }^{* 1}$ J. Jenko,† H. J. Huson,‡ D. R. Morrice,§ M. Bichard,\# \\ W. G. de L. Luff,Il and J. A. Woolliamst \\ *Animal Genomics and Improvement Laboratory, Agricultural Research Service, USDA, Beltsville, MD 20705-2350 \\ †The Roslin Institute, Royal (Dick) School of Veterinary Studies, University of Edinburgh, Easter Bush, Midlothian EH25 9RG, United Kingdom \\ ‡Department of Animal Science, Cornell University, Ithaca, NY 14853 \\ §Edinburgh Genomics, Ashworth Laboratories, University of Edinburgh, Edinburgh, EH9 3JT, United Kingdom \\ \#English Guernsey Cattle Society, Launceston, Cornwall PL15 9DP, United Kingdom \\ ॥World Guernsey Cattle Federation, Castel, Guernsey GY5 7JD, Channel Islands
}

\begin{abstract}
As of December 2015, 2,376 Guernsey bulls and cows had genotypes from collaboration between the United States, Canada, the United Kingdom, and the Isle of Guernsey. Of those, 439 bulls and 504 cows had traditional US evaluations, which provided sufficient data to justify investigation of the possible benefits of genomic evaluation for the Guernsey breed. Evaluation accuracy was assessed using a traditional 4-yr cutoff study. Twenty-two traits were analyzed ( 5 yield traits, 3 functional traits, and 14 conformation traits). Mean reliability gain over that for parent average was 16.8 percentage points across traits, which compares with 8.2, 18.5, 20.0, and 32.6 percentage points reported for Ayrshires, Brown Swiss, Jerseys, and Holsteins, respectively. Highest Guernsey reliability gains were for rump width (44.5 percentage points) and dairy form (40.5 percentage points); lowest gains were for teat length (1.9 percentage points) and rear legs (side view) $(2.3$ percentage points). Slight reliability losses (1.5 to 4.5 percentage points) were found for udder cleft, final score, and udder depth as well as a larger loss (13.6 percentage points) for fore udder attachment. Twentyone single nucleotide polymorphisms were identified for Guernsey breed determination and can be used in routine genotype quality control to confirm breed and identify crossbreds. No haplotypes that affect fertility were identified from the current data set. Principal component analysis showed some divergence of US and Isle of Guernsey subpopulations. However, the overlap of US, Canadian, UK, and Isle of Guernsey subpopulations indicated the presence of gene flow, and the
\end{abstract}

Received September 24, 2015.

Accepted March 24, 2016.

${ }^{1}$ Corresponding author: george.wiggans@ars.usda.gov similarities in the subpopulations supports a common genomic evaluation system across the regions.

Key words: Guernsey, breed determination, genomic evaluation, principal component analysis, population structure

\section{INTRODUCTION}

Official genomic evaluations of dairy cattle in the United States have been available for Brown Swiss, Holsteins, and Jerseys since 2009 and for Ayrshires since 2013 (Wiggans et al., 2011; Cooper et al., 2014). As of December 2015, 2,376 Guernsey bulls and cows had genotypes from collaboration between the United States, Canada, the United Kingdom, and the World Guernsey Cattle Federation (Isle of Guernsey); $85 \%$ (213 bulls and 1,807 cows) had been born in 2000 or later (Table 1). Of those genotyped, 439 bulls and 504 cows had traditional evaluations with reliabilities of 85 and $52 \%$ for milk yield, 76 and $43 \%$ for SCS, 69 and $41 \%$ for productive life, 63 and $33 \%$ for daughter pregnancy rate, and 82 and $54 \%$ for final score, respectively. That amount of data justified investigation of the possible benefits of genomic evaluation for the Guernsey breed. The objectives of the current study were to evaluate the accuracy of genomic predictions, select SNP for breed validation, identify haplotypes that affect fertility, and investigate population structure among the different geographical groups of Guernsey cattle.

\section{MATERIALS AND METHODS}

Genotypes determined with the Illumina BovineHD (Illumina Inc., 2015), Illumina BovineSNP50 (version 2; Illumina Inc., 2016), GoldenGate Bovine3K (Illumina Inc., 2011), GeneSeek Genomic Profiler (versions 1, 2, and 3; Neogen Corporation, 2014), and GeneSeek 
Table 1. Guernsey genotypes available for calculation of genetic evaluations as of December 2015 by birth year and animal sex

\begin{tabular}{lrrr}
\hline Birth year & $\begin{array}{c}\text { Bulls } \\
\text { (no.) }\end{array}$ & $\begin{array}{c}\text { Cows } \\
\text { (no.) }\end{array}$ & $\begin{array}{c}\text { All animals } \\
\text { (no. })\end{array}$ \\
\hline$<1960$ & 7 & 0 & 7 \\
$1960-1969$ & 32 & 0 & 32 \\
$1970-1979$ & 60 & 0 & 60 \\
$1980-1989$ & 94 & 2 & 96 \\
$1990-1999$ & 141 & 20 & 161 \\
2000 & 19 & 2 & 21 \\
2001 & 10 & 8 & 18 \\
2002 & 20 & 23 & 43 \\
2003 & 18 & 28 & 46 \\
2004 & 14 & 48 & 62 \\
2005 & 19 & 80 & 99 \\
2006 & 21 & 114 & 135 \\
2007 & 12 & 183 & 195 \\
2008 & 15 & 233 & 248 \\
2009 & 11 & 350 & 361 \\
2010 & 14 & 376 & 390 \\
2011 & 13 & 328 & 341 \\
2012 & 11 & 22 & 33 \\
2013 & 10 & 3 & 13 \\
2014 & 5 & 8 & 13 \\
2015 & 1 & 1 & 2 \\
All & 547 & 1,829 & 2,376 \\
\hline
\end{tabular}

Genomic Profiler HD (versions 1 and 2; Neogen Corporation, 2013) beadchips were available for 2,376 Guernseys as of December 2015. The majority $(1,301)$ of the genotypes were from the GeneSeek Genomic Profiler (version 3) chip.

Genotypes were imputed to a common set of 60,671 SNP using the findhap.f90 program (version 3; VanRaden, 2016) as is done for official US genomic evaluations of Ayrshires, Brown Swiss, Holsteins, and Jerseys. Individuals were processed from oldest to youngest, with known haplotypes of close ancestors checked first. If ancestor haplotypes were not available or did not match an individual's genotype, the most frequent haplotype without a conflict was chosen from all haplotypes by descending frequency. The selected haplotype's alleles were removed to determine the alternate haplotype for the genotype.

The 60,671 SNP were the same SNP set that was used for official December 2015 US genomic evaluations. That set of SNP had been selected based on SNP performance criteria, such as minor allele frequency, parent-progeny conflict, call rate, and correlation with other SNP of Brown Swiss, Holsteins, and Jerseys (Wiggans et al., 2014). Imputation rate was defined as percentage of SNP that were called after imputation to 60,671 SNP.

Accuracy of genomic evaluations was assessed with a traditional 4-yr cutoff study (VanRaden et al., 2009). The training set was genotyped Guernseys (bulls and cows) with a traditional evaluation as of August 2011.
The validation set was bulls with a traditional evaluation in December 2015 but no traditional evaluation in August 2011. Genomic evaluations and parent averages from the training set were compared for ability to predict December 2015 evaluations of the validation set. Twenty-two traits were analyzed: 5 yield traits (milk, fat, and protein yields and fat and protein percentages), 3 functional traits (productive life, SCS, and daughter pregnancy rate), and 14 conformation traits [final score, stature, strength, dairy form, rump angle, rump width, rear legs (side view), foot angle, fore udder attachment, rear udder height, udder cleft, udder depth, front teat placement, and teat length]. Individual SNP effects were estimated with the same method (approximate BayesA) used for US national genomic evaluations (VanRaden et al., 2009); for missing SNP, the mean allele frequency of the population was substituted so that those SNP would not have an effect on SNP estimates. Depending on trait, the training set to estimate individual SNP effects ranged from 513 to 588 genotyped bulls and cows (Table 2). The validation sets included 41 bulls for daughter pregnancy rate and 43 bulls for all other traits. Genomic evaluations were computed by a selection index using direct genomic predictions, traditional PTA, and a subset of PTA for only genotyped animals (VanRaden et al., 2009). Polygenic effects were assumed to explain $10 \%$ of the genetic variance. Realized genomic reliability was calculated using the method of VanRaden et al. (2009) and were based on coefficients of determination for 2011 predictions with 2015 daughter deviations after adjusting for error variance in the daughter deviations and for prior selection on pedigree. Reliability gains were calculated as the difference between realized genomic reliability, which included SNP and polygenic effects estimated from the August 2011 training set and August 2011 traditional parent averages, and the reliability of traditional parent averages for the validation set.

To select SNP that could be used for breed determination, homozygote frequencies were compared by SNP for 2,281 Guernsey, 3,521 Ayrshire, 17,109 Brown Swiss, 613,596 Holstein, and 80,492 Jersey genotypes available in October 2014. To qualify as a Guernsey identifier SNP, the homozygote had to have a frequency of $\geq 90 \%$ for Guernseys and a frequency of $\leq 30 \%$ for Brown Swiss, Holsteins, Jerseys, and Ayrshires.

To examine haplotypes that could affect fertility, haplotype segments of 600,200 , and 75 markers were examined to find those segments with the highest frequency in the Guernsey population that were never homozygous (VanRaden et al., 2011). Based on actual mating patterns that created the genotyped individuals in the population, the expected number of homozygous 
Table 2. Numbers of genotyped Guernseys with a traditional evaluation as of August 2011 that were included in the training set to estimate individual SNP effects for Guernsey yield, functional, and conformation traits by animal sex

\begin{tabular}{llll}
\hline & $\begin{array}{c}\text { Bulls } \\
\text { (no.) }\end{array}$ & $\begin{array}{c}\text { Cows } \\
(\text { no. })\end{array}$ & $\begin{array}{c}\text { All animals } \\
\text { (no.) }\end{array}$ \\
Trait & & & \\
\hline Yield & 273 & 315 & 588 \\
Milk & 273 & 315 & 588 \\
Fat & 273 & 315 & 588 \\
Protein & 273 & 315 & 588 \\
Fat percentage & 273 & 315 & 588 \\
Protein percentage & & & \\
Functional & 258 & 226 & 484 \\
Productive life & 256 & 302 & 558 \\
SCS & 219 & 221 & 440 \\
Daughter pregnancy rate & & & \\
Conformation & 262 & 251 & 513 \\
Final score & 267 & 278 & 545 \\
Stature & 266 & 279 & 545 \\
Strength & 267 & 273 & 540 \\
Dairy form & 267 & 278 & 545 \\
Rump angle & 267 & 278 & 545 \\
Rump width & 260 & 280 & 540 \\
Rear legs (side view) & 258 & 281 & 539 \\
Foot angle & 266 & 279 & 545 \\
Fore udder attachment & 266 & 279 & 545 \\
Rear udder height & 262 & 277 & 539 \\
Udder cleft & 267 & 278 & 545 \\
Udder depth & 266 & 279 & 545 \\
Front teat placement & 267 & 274 & 541 \\
Teat length & & & \\
\hline
\end{tabular}

individuals was determined as the number of matings for carrier sire by carrier maternal grandsire divided by 4 for the region.

Principal component analysis (PCA) was performed to investigate population structure within the Guernsey breed based on whole-genome genotypes and to evaluate if common predictions were appropriate across the various regional subpopulations. Principal components were estimated using Golden Helix SVS software (ver- sion 8.4.0; Golden Helix, 2015), which uses similar methodology to the EIGENSTRAT program of Price et al. (2006). Population divergence was assessed in a pairwise comparison using the fixation index $\left(\mathbf{F}_{\mathbf{S T}}\right)$ of Weir and Cockerham (1984), which also was calculated using Golden Helix SVS. Values close to 0 represented no divergence between subpopulations; values close to 1 represented complete isolation or genetic segregation of subpopulations.

\section{RESULTS AND DISCUSSION}

Mean imputation rate for Guernsey genotypes (Table 3) ranged from 79.2 to $99.9 \%$ depending on the genotype chip used. In general, chips that included more of the 60,671 SNP used for US genomic evaluations had higher imputation accuracies. For chips with genotypes from >100 animals, animals genotyped with the GeneSeek Genomic Profiler HD (version 2) chip had the highest imputation rates (97.3 to 99.9\%). Imputed dams had the lowest mean imputation rate $(92.6 \%)$ because their genotypes were derived completely from parent and progeny genotypes. However, imputation rates for imputed dams were much higher for Guernseys than reported for Ayrshires (78.9\%; Cooper et al., 2014). Guernsey imputation rates were similar to those for simulated Holstein genotypes (VanRaden et al., 2013) for imputed dams and all chip types except Bovine3K, which was higher for Guernseys most likely because only 3 Guernsey Bovine3K genotypes were available. All 60,671 SNP were used in imputation and SNP effect calculation to maintain consistency with the SNP set used for routine evaluation of Brown Swiss, Holsteins, Jerseys, and Ayrshires even though some SNP were monomorphic for Guernseys. For Guernseys,

Table 3. Imputation rates ${ }^{1}$ for Guernseys after imputation to the 60,671 SNP used for US genomic evaluations in December 2015 by genotyping chip

\begin{tabular}{|c|c|c|c|c|c|c|}
\hline \multirow[b]{2}{*}{ Genotyping chip } & \multirow{2}{*}{$\begin{array}{l}\text { SNP } \\
\text { (no.) }\end{array}$} & \multirow{2}{*}{$\underset{(\text { no. })}{\text { Animals }}$} & \multicolumn{4}{|c|}{ Imputation rate $(\%)$} \\
\hline & & & Mean & $\mathrm{SD}$ & Minimum & Maximum \\
\hline BovineSNP50, version $2^{2}$ & 43,276 & 157 & 98.8 & 1.3 & 92.5 & 99.9 \\
\hline GoldenGate Bovine $3 \mathrm{~K}^{2}$ & 2,710 & 3 & 96.7 & 4.0 & 92.0 & 99.0 \\
\hline BovineHD ${ }^{2}$ & 55,675 & 135 & 98.8 & 1.2 & 91.4 & 99.9 \\
\hline GeneSeek Genomic Profiler ${ }^{3}$ & 8,051 & 2 & 99.2 & 0.1 & 99.2 & 99.3 \\
\hline GeneSeek Genomic Profiler $\mathrm{HD}^{3}$ & 43,957 & 501 & 96.7 & 3.9 & 83.0 & 99.9 \\
\hline GeneSeek Genomic Profiler, version $2^{3}$ & 8,427 & 153 & 97.3 & 2.6 & 80.6 & 99.6 \\
\hline GeneSeek Genomic Profiler, version $3^{3}$ & 13,136 & 1,301 & 94.0 & 2.5 & 79.2 & 99.0 \\
\hline GeneSeek Genomic Profiler HD, version $2^{3}$ & 56,056 & 112 & 99.7 & 0.3 & 97.3 & 99.9 \\
\hline Imputed dams ${ }^{4}$ & - & 12 & 92.6 & 3.3 & 85.6 & 97.9 \\
\hline
\end{tabular}

${ }^{1}$ Percentage of SNP that were called after imputation to 60,671 SNP.

${ }^{2}$ Illumina Inc. (San Diego, CA).

${ }^{3}$ Neogen Corporation (Lansing, MI).

${ }^{4}$ Imputed from genotypes of parents and progeny. 
Table 4. Mean reliabilities for August 2011 traditional parent averages and reliability gains ${ }^{1}$ for genomic evaluations $^{2}$ of Guernsey bulls without daughter information in August 2011 but with a traditional evaluation by December 2015 for yield, functional, and conformation traits

\begin{tabular}{|c|c|c|c|}
\hline \multirow[b]{2}{*}{ Trait } & \multicolumn{2}{|c|}{ Reliability (\%) } & \multirow{2}{*}{$\begin{array}{l}\text { Reliability gain } \\
\text { (percentage points) }\end{array}$} \\
\hline & Parent average & Genomic & \\
\hline \multicolumn{4}{|l|}{ Yield } \\
\hline Milk & 34.5 & 66.2 & 31.7 \\
\hline Fat & 34.5 & 42.5 & 8.0 \\
\hline Protein & 34.5 & 60.2 & 25.7 \\
\hline Fat percentage & 34.5 & 64.9 & 30.4 \\
\hline Protein percentage & 34.5 & 46.5 & 12.0 \\
\hline Mean & - & - & 21.6 \\
\hline \multicolumn{4}{|l|}{ Functional } \\
\hline Productive life & 26.5 & 59.6 & 33.1 \\
\hline SCS & 29.7 & 51.4 & 21.7 \\
\hline Daughter pregnancy rate & 23.5 & 40.9 & 17.4 \\
\hline Mean & - & - & 24.1 \\
\hline \multicolumn{4}{|l|}{ Conformation } \\
\hline Final score & 34.0 & 31.0 & -3.0 \\
\hline Stature & 37.6 & 71.8 & 34.2 \\
\hline Strength & 35.1 & 71.0 & 35.9 \\
\hline Dairy form & 35.9 & 76.4 & 40.5 \\
\hline Rump angle & 36.8 & 52.6 & 15.8 \\
\hline Rump width & 35.7 & 80.2 & 44.5 \\
\hline Rear legs (side view) & 31.4 & 33.7 & 2.3 \\
\hline Foot angle & 29.6 & 49.6 & 20.0 \\
\hline Fore udder attachment & 35.6 & 22.0 & -13.6 \\
\hline Rear udder height & 34.7 & 44.7 & 10.0 \\
\hline Udder cleft & 33.3 & 31.8 & -1.5 \\
\hline Udder depth & 36.5 & 32.0 & -4.5 \\
\hline Front teat placement & 35.2 & 42.0 & 6.8 \\
\hline Teat length & 36.0 & 37.9 & 1.9 \\
\hline Mean & - & - & 13.5 \\
\hline Mean for all traits & - & - & 16.8 \\
\hline
\end{tabular}

minor allele frequency was $\leq 0.01$ for $7.9 \%$ of SNP and $\leq 0.05$ for $16.1 \%$.

Mean reliability gain over parent average (Table 4) was 16.8 percentage points across traits, with mean reliability gains of 21.6 percentage points for yield traits, 24.1 percentage points for functional traits, and 13.5 percentage points for conformation traits. All individual traits gained in accuracy except for slight losses (1.5 to 4.5 percentage points) for udder cleft, final score, and udder depth and a larger loss (13.6 percentage points) for fore udder attachment. The largest gains were for rump width (44.5 percentage points) and dairy form (40.5 percentage points). Traits with the smallest gains were teat length (1.9 percentage points) and rear legs (side view) (2.3 percentage points). Mean reliability gain across traits for Guernseys (16.8 percentage points) was larger than the mean for Ayrshires (8.2 percentage points; Cooper et al., 2014) but slightly smaller than the means for Brown Swiss (18.5 percentage points; Wiggans et al., 2012), Jerseys (20.0 percentage points; Wiggans et al., 2015), and Holsteins (33.0 percentage points; Cooper et al., 2015). However, accuracy of genomic evaluations is affected by the size and composition of the reference population used to estimate SNP effects; for the previously mentioned breed reliability gains, the reference populations were 588 bulls and cows for Guernseys, 646 bulls for Ayrshires (Cooper et al., 2014), 5,627 bulls and cows for Brown Swiss (Council on Dairy Cattle Breeding, 2016), 5,779 bulls and cows for Jerseys (Wiggans et al., 2015), and 52,685 bulls and cows for Holsteins (Cooper et al., 2015). The inclusion of cows in the training set may have resulted in the greater reliability gain for Guernseys than for Ayrshires even though the Guernsey training set was smaller. Higher reliability gains have been reported for Holsteins when cows were included in the reference population instead of bulls only (Cooper et al., 2015).

Twenty-one SNP (Table 5) were identified for Guernsey breed determination as having 1 allele with a homozygous frequency of $\geq 90 \%$ for Guernseys and $\leq 30 \%$ for Holsteins, Jerseys, Brown Swiss, and Ayrshires. Fewer SNP qualified for breed determination of Guernseys 
COOPER ET AL.

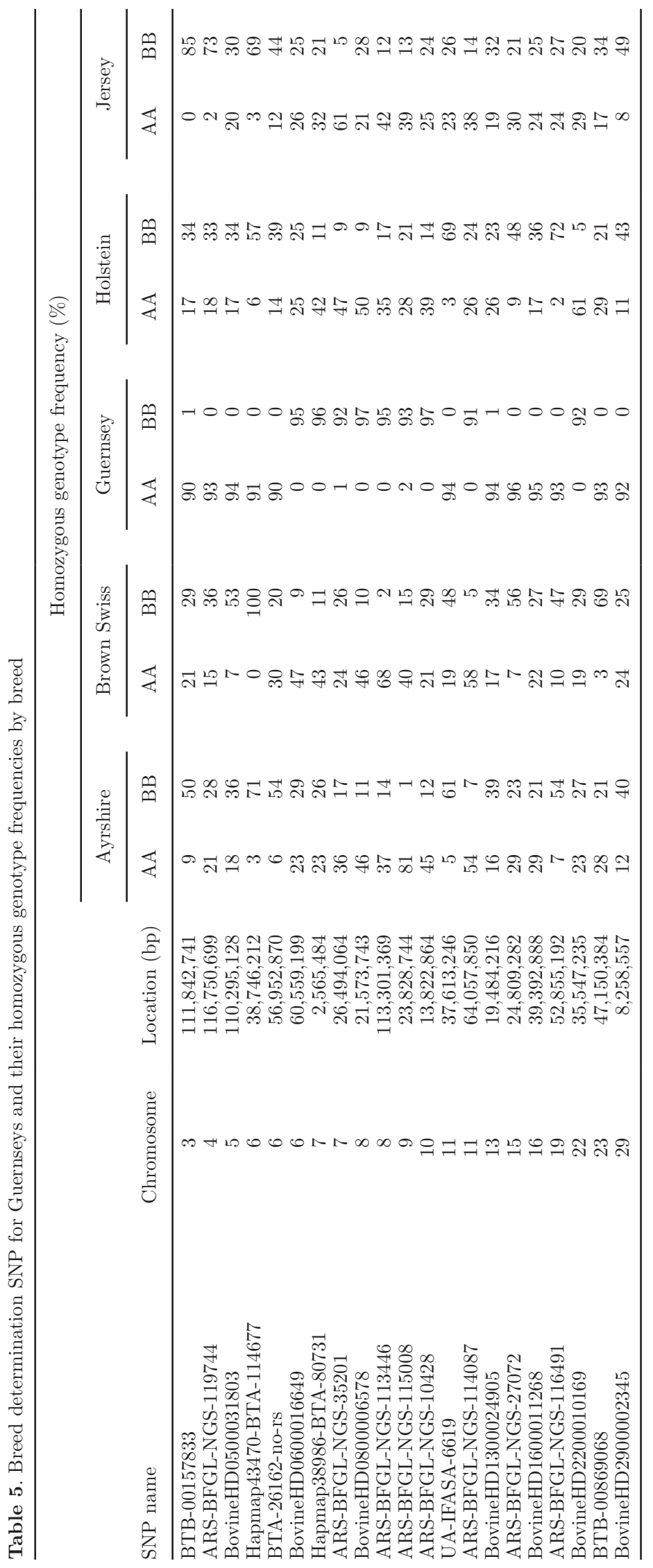


Table 6. Fixation index ${ }^{1}\left(\mathrm{~F}_{\mathrm{ST}}\right)$ for Guernsey populations by country of animal registration

\begin{tabular}{lcccc}
\hline Region & United States & Canada & United Kingdom & Isle of Guernsey \\
\hline United States & 0.000 & 0.008 & 0.016 & 0.011 \\
Canada & & 0.000 & 0.013 & 0.010 \\
United Kingdom & & 0.000 & 0.006 \\
Isle of Guernsey & & & 0.000 \\
\hline
\end{tabular}

${ }^{1}$ Lower values indicate a closer relationship.

compared with Holsteins, Jerseys, and Brown Swiss, which each have approximately 230 unique SNP on the Illumina BovineSNP50 chip (Wiggans et al., 2010). The fewer qualifying SNP for both Guernseys and Ayrshires (12 SNP; Cooper et al., 2014) resulted partially from increased difficulty in finding distinguishing SNP as more breeds were evaluated. The Council of Dairy Cattle Breeding (Bowie, MD) implemented use of the $21 \mathrm{SNP}$ in routine procedures for genotype quality control to confirm breed and identify crossbreds in October 2014.

No haplotypes that affect fertility were found within the Guernsey genotyped population. The lack of such homozygous haplotypes was surprising because of the high inbreeding coefficient for Guernseys ( $>7.0 \%$ for cows born since 2010; Council on Dairy Cattle Breeding, 2015e) and downward trends for Guernsey daughter pregnancy rate, cow conception rate, and heifer conception rate (Council on Dairy Cattle Breeding, 2015b,c,d). With routine genomic evaluation of Guernseys, which began in April 2016 (Council on Dairy Cattle Breeding, 2015a), genotypes will be checked monthly for haplotypes that affect fertility, and such haplotypes may be detected as data accumulate.

Surprisingly, a major QTL was discovered on chromosome 19 near 27,000,000 bp. This QTL had as big an effect as the diacylglycerol O-acyltransferase 1 gene but affected many more traits (milk, productive life, SCS, daughter pregnancy rate, cow conception rate, size, rump, udder, and teat length). However, net merit was not affected, which indicated that the trait effects must almost cancel each other out (P. M. VanRaden, Animal Genomics and Improvement Laboratory, Agricultural Research Service, USDA, Beltsville, MD, personal communication).

The PCA showed minimal structure within the Guernsey breed, with no complete segregation of individuals reflective of geographic origin (Figure 1). Principal component 1 identified the main genetic variation between US and Isle of Guernsey subpopulations, which represented the most individuals (832 US Guernseys and 1,405 island Guernseys). Principal component 2 indicated genetic variation among individual animals within the subpopulations. A tail to the right was evident for island Guernseys, which demonstrates a genetic distinction between those individuals and Guernseys from other regions. A few of the UK Guernseys clustered with the island tail animals, which indicated greater genetic similarity; the remaining UK animals clustered where US and island subpopulations overlapped. The Canadian subpopulation was more segregated but generally clustered with US Guernseys. In general, the clusterings of UK with island Guernseys and Canadian with US Guernseys show an increased genetic similarity among the animals within the subpopulations.

The $\mathrm{F}_{\mathrm{ST}}$ estimates (Table 6) support the PCA results. The UK and island Guernseys had the closest relationship with an $\mathrm{F}_{\mathrm{ST}}$ of 0.006 , and US and Canadian Guernseys were genetically similar with an $\mathrm{F}_{\mathrm{ST}}$ of 0.008. Pair-wise comparisons of US or Canadian animals with UK or island animals had $\mathrm{F}_{\mathrm{ST}}$ values of approximately 0.01 . Although some genetic differentiation was observed, the substantial overlap of subpopulations indicates a gene flow among all regions. The similarities in the subpopulations also support a common genomic evaluation system across regions.

\section{CONCLUSIONS}

Genomic evaluations were calculated for 2,376 US, Canadian, UK, and island Guernsey bulls and cows with genotypes as of December 2015. Reliability gain for genomic evaluations over parent averages was 16.8 percentage points across all traits. A group of 21 SNP were identified that can be used in breed determination. No haplotypes that affect fertility were identified from the current data set; however, a routine check for such haplotypes will be conducted monthly when genomic evaluations for Guernseys are calculated by the Council on Dairy Cattle Breeding. Some divergence was observed between US and Isle of Guernsey subpopulations. However, the overlap of regional subpopulations indicates the presence of gene flow, and subpopulation similarities support a common genomic evaluation system across regions. The use of genomics in Guernsey genetic evaluations is expected to increase the use of young bulls, reduce generation interval, and 


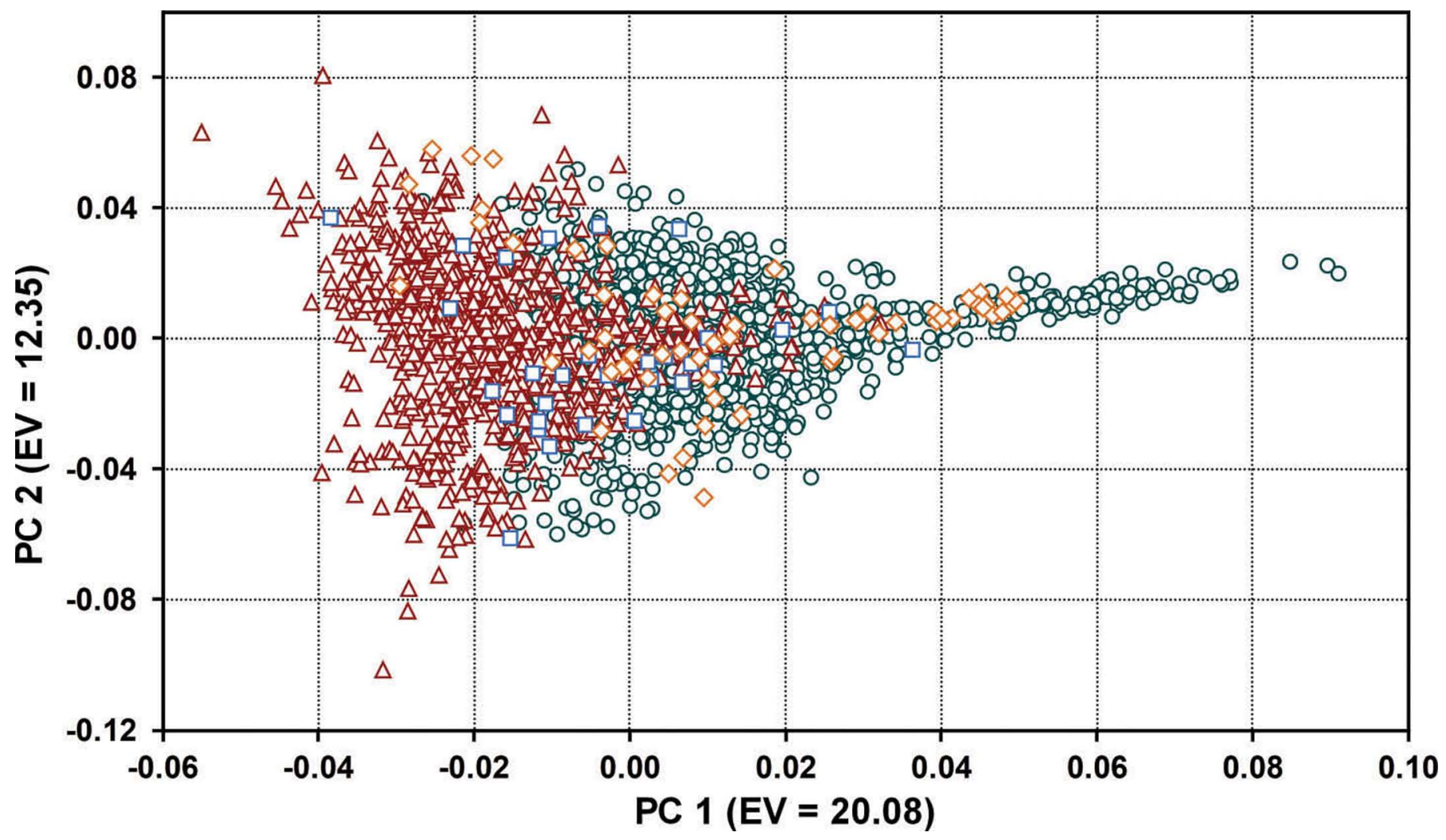

Figure 1. Principal component analysis of Guernsey cattle population based on the animal's country of registration: Canada ( $\square$ ), Isle of Guernsey $(\bigcirc)$, United Kingdom $(\diamond)$, and United States $(\Delta)$. Principal component 1 (PC 1, x-axis) distinguishes Isle of Guernsey from United States subpopulations; principal component 2 (PC 2, y-axis) indicates genetic variation among individual animals within subpopulations. Color version available online.

increase the rate of genetic improvement. The benefits of genomic evaluation will increase as more Guernsey breeders genotype their animals.

\section{ACKNOWLEDGMENTS}

The research leading to these results has received funding from the European Union's Seventh Framework Programme for research, technological development and demonstration under grant agreement no. 289592-Gene2Farm. The authors thank Select Sires (Plain City, $\mathrm{OH}$ ) and the American Guernsey Association (Columbus, $\mathrm{OH}$ ) for project development and providing genotypes; the Council on Dairy Cattle Breeding (Bowie, MD) for supplying pedigree, performance, and genotypic data; and S. M. Hubbard (Animal Genomics and Improvement Laboratory, Agricultural Research Service, USDA, Beltsville, MD) for technical manuscript review. T. A. Cooper and G. R. Wiggans were supported by USDA Agricultural Research Service appropriated project 1245-31000-101-00, "Improving Genetic Predictions in Dairy Animals Using Phenotypic and Genomic Information." The figure was created using Daniel's XL Toolbox add-in for Excel (version 6.60) by Daniel Kraus (Würzburg, Germany). Mention of trade names or commercial products in this article is solely for the purpose of providing specific information and does not imply recommendation or endorsement by USDA.

\section{REFERENCES}

Cooper, T. A., G. R. Wiggans, D. J. Null, J. L. Hutchison, and J. B. Cole. 2014. Genomic evaluation, breed identification, and discovery of a haplotype affecting fertility for Ayrshire dairy cattle. J. Dairy Sci. 97:3878-3882.

Cooper, T. A., G. R. Wiggans, and P. M. VanRaden. 2015. Short communication: Analysis of genomic predictor population for Holstein dairy cattle in the United States - Effects of sex and age. J. Dairy Sci. 98:2785-2788.

Council on Dairy Cattle Breeding. 2015a. CDCB update, November 24, 2015: Actions from the CDCB board meeting (November 12, 2015). Accessed Jan. 14, 2016. https://www.cdcb.us/ News/2015_11_12_CDCB\%20board\%20Actions\%20v1.2.pdf.

Council on Dairy Cattle Breeding. 2015b. Trend in cow conception rate for Guernsey, calculated August 2015. Accessed Jan. 13 , 2016. https://www.cdcb.us/eval/summary/trend.cfm?R Menu=GU.c\#StartBody.

Council on Dairy Cattle Breeding. 2015c. Trend in daughter preg rate for Guernsey, calculated August 2015. Accessed Jan. 
13, 2016. https://www.cdcb.us/eval/summary/trend.cfm?R_ Menu=GU.d\#StartBody.

Council on Dairy Cattle Breeding. 2015d. Trend in heifer conception rate for Guernsey, calculated August 2015. Accessed Jan. 13, 2016. https://www.cdcb.us/eval/summary/trend.cfm?R_ Menu=GU.h\#StartBody.

Council on Dairy Cattle Breeding. 2015e. Trend in inbreeding coefficients of cows for Guernsey, calculated August 2015. Accessed Jan. 13, 2016. https://www.cdcb.us/eval/summary/inbrd.cfm?R_ Menu=GU\#StartBody.

Council on Dairy Cattle Breeding. 2016. Genotypes included in evaluations by breed, chip density, presence of phenotypes (old vs. young), and evaluation year-month (cumulative). Accessed Jan. 13, 2016. https://www.cdcb.us/Genotype/cur_density.html.

Golden Helix. 2015. Principal component analysis. SNP \& Variation Suite Manual, version 8.4.0. Accessed Apr. 22, 2015. http://doc. goldenhelix.com/SVS/8.4.0/svs_index.html.

Illumina Inc. 2011. GoldenGate Bovine3K Genotyping BeadChip. Accessed Sep. 16, 2015. http://www.illumina.com/documents/ products/datasheets/datasheet_bovine3k.pdf

Illumina Inc. 2015. BovineHD Genotyping BeadChip. Accessed Sep. 16, 2015. http://www.illumina.com/Documents/products/ datasheets/datasheet_bovineHD.pdf.

Illumina Inc. 2016. BovineSNP50 Genotyping BeadChip. Accessed Apr. 22, 2016. http://www.illumina.com/Documents/products/ datasheets/datasheet_bovine_snp5O.pdf.

Neogen Corporation. 2013. GeneSeek Genomic Profiler HD for Dairy Cattle. Accessed Sep. 16, 2015. http://www.neogen.com/ Agrigenomics/pdf/Slicks/GGP_HD_Dairy.pdf.

Neogen Corporation. 2014. GeneSeek Genomic Profiler for Dairy Cattle. Accessed Apr. 22, 2016. http://www.neogen.com/ Agrigenomics/pdf/Slicks/GGP-LD_Dairy.pdf.

Price, A. L., N. J. Patterson, R. M. Plenge, M. E. Weinblatt, N. A. Shadick, and D. Reich. 2006. Principal components analysis corrects for stratification in genome-wide association studies. Nat. Genet. 38:904-909.

VanRaden, P. M. 2016. findhap.f90, Find haplotypes and impute genotypes using multiple chip sets and sequence data. Accessed Apr. 22, 2016. http://aipl.arsusda.gov/software/findhap/.
VanRaden, P. M., D. J. Null, M. Sargolzaei, G. R. Wiggans, M. E. Tooker, J. B. Cole, T. S. Sonstegard, E. E. Connor, M. Winters, J. B. C. H. van Kaam, A. Valentini, B. J. Van Doormaal, M. A. Faust, and G. A. Doak. 2013. Genomic imputation and evaluation using high-density Holstein genotypes. J. Dairy Sci. 96:668-678.

VanRaden, P. M., K. M. Olson, D. J. Null, and J. L. Hutchison. 2011. Harmful recessive effects on fertility detected by absence of homozygous haplotypes. J. Dairy Sci. 94:6153-6161.

VanRaden, P. M., C. P. Van Tassell, G. R. Wiggans, T. S. Sonstegard, R. D. Schnabel, J. F. Taylor, and F. S. Schenkel. 2009. Invited review: Reliability of genomic predictions for North American Holstein bulls. J. Dairy Sci. 92:16-24.

Weir, B. S., and C. C. Cockerham. 1984. Estimating F-statistics for the analysis of population structure. Evolution 38:1358-1370.

Wiggans, G., P. VanRaden, and J. Hutchison. 2012. Additional Brown Swiss genotypes from Interbull. Changes to evaluation system (August 2012). Accessed Sep. 23, 2015. http://aipl.arsusda.gov/ reference/changes/eval1208.htm.

Wiggans, G. R., T. A. Cooper, D. J. Null, and P. M. VanRaden. 2014. Increasing the number of single nucleotide polymorphisms used in genomic evaluations of dairy cattle. Proc. 10th World Congr. Genet. Appl. Livest. Prod., Vancouver, Canada, Comm. 301. Amer. Soc. Anim. Sci., Champaign, IL. Accessed Sep. 16 2015. https://asas.org/docs/default-source/wcgalp-proceedingsoral/301_paper_9522_manuscript_742_0.pdf.

Wiggans, G. R., G. Su, T. A. Cooper, U. S. Nielsen, G. P. Aamand, B. Guldbrandtsen, M. S. Lund, and P. M. VanRaden. 2015. Short communication: Improving accuracy of Jersey genomic evaluations in the United States and Denmark by sharing reference population bulls. J. Dairy Sci. 98:3508-3513.

Wiggans, G. R., P. M. VanRaden, L. R. Bacheller, M. E. Tooker, J. L. Hutchison, T. A. Cooper, and T. S. Sonstegard. 2010. Selection and management of DNA markers for use in genomic evaluation. J. Dairy Sci. 93:2287-2292.

Wiggans, G. R., P. M. VanRaden, and T. A. Cooper. 2011. The genomic evaluation system in the United States: Past, present, future. J. Dairy Sci. 94:3202-3211. 